\title{
Alinhamento Estratégico entre os Planos de Negócio e de Tecnologia de Informação: um Modelo Operacional para Implementação
}

\author{
Ângela F. Brodbeck \\ Norberto Hoppen
}

\begin{abstract}
Resumo
O alinhamento estratégico, aliado ao planejamento estratégico, é um importante instrumento de gestão. Por isso, novas abordagens para a operacionalização do alinhamento podem auxiliar a gestão corporativa em suas decisões e influir no desempenho organizacional. Este estudo, de natureza exploratória, teve por objetivo desenvolver um modelo operacional de alinhamento estratégico entre objetivos e estratégias de negócio e de tecnologia de informação, no qual convergem elementos promotores de alinhamento dos modelos clássicos de alinhamento estratégico, estudos sobre metodologia de implementação de planos estratégicos e de sistemas integrados de informação e resultados obtidos por meio da observação da promoção de alinhamento em múltiplos estudos de caso. Os principais resultados encontrados mostram que as organizações estão promovendo o alinhamento estratégico com maior ou menor intensidade, mesmo que de forma empírica e parcial; apontam os elementos metodologia e instrumentação da gestão como principais promotores de alinhamento durante a etapa de implementação do processo de planejamento; e revelam a importância destes dois elementos no comprometimento das pessoas envolvidas no processo de planejamento e no atingimento das metas planejadas.
\end{abstract}

Palavras-chaves: alinhamento estratégico; planejamento estratégico; tecnologia de informação; implementação.

\begin{abstract}
Strategic alignment, combined to strategic planning, is an important management tool. For this reason new approaches to strategic alignment promotion could help high-level management decisions and affect the organizational performance. This study of exploratory nature aims to develop an operational model of strategic alignment between business strategies and goals and information technology strategies and goals. To this model converge elements from classical strategic alignment models, studies about methodologies of strategic planning implementation, methodologies of integrated information systems implementation and findings from multiple case studies. The main results show that organizations always promote strategic alignment, with more or less intensity, even in an empirical and partial way. The most important alignment promoters to the implementation phase of strategic planning are the elements methodology and management tools, which can influence the commitment of the personnel involved in the planning process and positively affect achievement of goals.
\end{abstract}

Key words: strategic alignment; strategic planning; information technology; implementation. 


\section{A Importância do Alinhamento Estratégico}

O impacto da tecnologia de informação (TI) no desempenho dos negócios tem sido bastante discutido durante esta última década. Pesquisadores das áreas de negócio e de TI realizam estudos para examinar as necessidades e os benefícios do alinhamento da TI com o restante dos negócios (Reich e Benbasat, 1996; Sabherwal e Chan, 2001). Os executivos de TI também têm considerado o alinhamento entre as estratégias de negócio e de TI como um dos objetivos principais da área, pela possibilidade de identificação de novas oportunidades de negócios e pela obtenção de vantagens competitivas baseadas em soluções de TI (Niederman, Brancheau e Wetherbe, 1991; Porter, 2001).

Entretanto, apesar da concordância geral sobre o impacto positivo do alinhamento nas organizações, ainda existem alguns elementos inibidores do processo como um todo, tais como problemas de comunicação, perda de recursos ou de comprometimento (Lederer e Sethi, 1996; Reich e Benbasat, 1996). As pesquisas empíricas focadas no método ou modelo de promoção do alinhamento estratégico, ainda são esparsas e fragmentadas. Também vale destacar as pesquisas realizadas pelo Gartner Group (2002), nas quais se constata que uma grande parte das empresas continuam apresentando alinhamento limitado. O exemplo a seguir, observado recentemente em nosso trabalho de pesquisa, ilustra o tema.

“A Presidência de uma empresa de planos e saúde encontra-se frente a grandes perdas de clientes para a concorrência. Ela necessita de informações sobre os motivos e para qual(is) concorrente(s) ocorre a perda. Os altos executivos decidem criar indicadores e medidas que permitam promover a fidelização dos clientes, requisitando à TI que garimpe em sua base de dados, preferências de médicos e serviços, volume de utilização, reclamações, entre outros. Atualmente, os sistemas comportam uma base de dados contratuais dos clientes, uma base cadastral de médicos prestadores de serviços e uma base de produção dos médicos (volume de atendimentos). Porém não existe a relação entre a base de clientes e a de produção dos médicos, o registro dos motivos que um cliente abandona ou encerra o contrato, nem a possibilidade de saber os tipos de contato estabelecidos com os clientes pelo Setor de Relacionamento com Clientes (reclamações, autorizações, esclarecimentos dos planos, preços, entre outros)".

O cenário mostra um alinhamento baixo entre uma necessidade da Presidência 
da empresa, que se transformou em uma estratégia de negócio, e as funcionalidades do sistema de informação para suportá-la. Muitas vezes, este tipo de deficiência da TI leva os executivos de negócio a criarem seus próprios departamentos de TI, adquirindo seus próprios sistemas, alimentando uma base de dados própria, que deverá conter dados redundantes para a base de dados corporativa. Deste modo, o problema pode estar supostamente resolvido, mas de forma ineficiente e redundante, gerando retrabalho e custos de operação do negócio elevados. Deixa-se assim de utilizar o potencial da TI como uma aplicação de novos canais para fazer negócio e como viabilizadora de redução de custos da operação desses negócios.

Pressupondo a importância do alinhamento para o desempenho organizacional como um todo, esta pesquisa buscou observar como o alinhamento vem sendo promovido pelas empresas durante o processo de planejamento estratégico. Desta forma, o presente estudo centrou-se em dois aspectos: (1) repensar os processos de planejamento isolados das áreas de negócio e de TI, transformando-os em um processo único, com promoção de alinhamento total durante a etapa de formulação do processo de planejamento; e (2) como promover este alinhamento durante a etapa de implementação de maneira contínua e permanente ao longo de todo o horizonte de planejamento.

Assim, o objetivo principal desta pesquisa foi estruturar e operacionalizar um modelo de promoção do alinhamento estratégico entre os planos estratégicos de negócio e de TI, estendido para a etapa de implementação do processo de planejamento estratégico. Para isto, foram consideradas as variáveis que identificam o alinhamento estratégico durante a etapa de formulação dos planos de negócio e de TI e variáveis adicionais, que identificam o alinhamento estratégico durante a etapa de implementação dos objetivos e estratégias dos planos de negócio, extraídas dos estudos sobre metodologias de implementação de planejamento estratégico e de sistemas de informações integrados.

O texto a seguir encontra-se organizado do seguinte modo: inicialmente descreve-se o arcabouço conceitual do alinhamento estratégico; após apresenta-se a metodologia de pesquisa, os estudos de caso e seus resultados e o modelo de operacionalização do alinhamento estratégico; por fim, são desenvolvidas as contribuições práticas e teóricas e uma breve conclusão da pesquisa.

\section{Alinhamento Estratégico}

Alguns dos conceitos mais significativos sobre alinhamento encontrados na li- 
teratura, são: (1) o alinhamento entre o plano estratégico de negócio (PEN) e o plano estratégico de tecnologia de informação (PETI) é alcançado quando o conjunto de estratégias de sistemas - objetivos, obrigações e estratégias - é derivado do conjunto estratégico organizacional - missão, objetivos e estratégias (King, 1988); (2) o elo entre PEN-PETI corresponde ao grau no qual a missão, os objetivos e os planos de TI refletem, suportam e são suportados pela missão, pelos objetivos e pelos planos de negócio (Reich e Benbasat, 1996); (3) o alinhamento estratégico corresponde à adequação e integração funcional entre ambiente externo (mercados) e interno (estrutura administrativa e recursos financeiros, tecnológicos e humanos) para desenvolver as competências e maximizar o desempenho organizacional (Henderson e Venkatraman, 1993); e (4) o alinhamento entre PEN-PETI é a adequação da orientação estratégica do negócio com a de TI (Chan et al., 1997).

O alinhamento pode ser encontrado nas organizações em diversos estágios ou níveis, cabendo destacar dois naquelas organizações que almejam desenvolvê-lo. O primeiro nível é o de integração operacional, para o qual há a necessidade de planos operacionais de negócio e de TI. Para a sua operacionalização, o PETI é formulado seguindo as definições do PEN e, em seu próximo estágio de evolução, ambos os planos são formulados simultaneamente. Este nível é caracterizado pela especificação de requisitos e funções dos sistemas de informação (SI) e do negócio em nível operacional, abrangendo estrutura e processos organizacionais que usam a TI como suporte (Henderson e Venkatraman, 1993; Chan, 1999). Vale destacar que, nesta pesquisa, os sistemas de informação integrados (SII) foram considerados os promotores do alinhamento neste nível, uma vez que estão baseados na integração dos negócios pelos dados, pelos processos, por tarefas realizadas pelas pessoas e pelo redesenho organizacional (estrutura administrativa combinada com a tecnológica), permitindo alterar as regras do negócio (Ward e Griffiths, 1996).

O segundo nível de alinhamento estratégico mostra a idéia de integração em um nível mais alto de gestão, no qual a integração ocorre por meio da adequação estratégica dos objetivos da TI com as estratégias, objetivos e competências fundamentais do negócio. Neste caso, pode ocorrer redirecionamento do negócio por meio da TI (Henderson e Venkatraman, 1993; Teo, 1994). Neste nível, PEN e PETI deveriam ser integrados por meio do mapeamento dos sistemas e das informações estratégicas diretamente relacionadas com as estratégias de negócio, sustentando os objetivos do negócio e contribuindo significativamente para a identificação de novas oportunidades de negócio, baseadas em soluções de TI e na obtenção de vantagens competitivas (McFarlan, 1984; Porter, 2001).

O modelo de alinhamento estratégico no qual se fundamentou este estudo, foi o 
de Henderson e Venkatraman (1993), tendo o conceito de alinhamento estratégico sido baseado em duas suposições: (1) que o desempenho econômico está diretamente relacionado com a habilidade do gerenciamento para criar uma adequação estratégica (posição da organização no mercado competitivo suportada por uma estrutura administrativa adequada); e (2) que a adequação estratégica é essencialmente dinâmica. Assim, o alinhamento estratégico não é um evento isolado, mas um processo contínuo de adaptação e mudança. Isto nos conduz, novamente, à importância dos processos de revisão contínua (avaliação) para a promoção do alinhamento.

Outra contribuição teórica importante para o desenvolvimento do modelo operacional de alinhamento estratégico foi incorporada a partir das pesquisas sobre a metodologia e implementabilidade dos planos de SI (Lederer e Sethi, 1988), sobre níveis de integração entre negócio e TI (Teo, 1994) e sobre o gerenciamento da implementação dos planos estratégicos de SI (Gottschalck e Lederer, 1997). Estes estudos mostram o alinhamento como um elemento dentro do modelo de implementação de planos estratégicos de SI, desmembrado em variáveis metodológicas importantes, que podem justificar a sua continuidade, representada no modelo proposto pela sua promoção durante a etapa de implementação do processo de planejamento.

Nesta pesquisa, os elementos e variáveis considerados mais significativos para a promoção do alinhamento estratégico, foram agrupados em quatro conjuntos, apresentados a seguir.

- Elementos de Contexto Organizacional: estes elementos representam a promoção do alinhamento por meio de variáveis que permitem observar as condições e o direcionamento geral do negócio, tais como porte, estratégias, custos operacionais, investimentos, tipologias organizacionais, cultura e autonomia local e posicionamento de mercado (Henderson e Venkatraman, 1993; Brown e Magill, 1994).

- Elementos de Modelo de Planejamento Estratégico: estes elementos representam a promoção do alinhamento por meio de variáveis que permitem definir o modelo e o processo de planejamento, tais como componentes do PEN (estratégias, objetivos e metas, planos de ação), componentes do PETI (infra-estrutura de suporte, sistemas e processos, pessoas), metodologia do processo de planejamento (etapas, participação e comprometimento, reuniões), horizonte e ambiente de planejamento (Boar, 1994; King,1988).

. Elementos da Etapa de Formulação do Processo de PE: estes elementos representam a promoção do alinhamento por meio de variáveis de adequação estratégica, de integração funcional (SII) e de consistência entre os itens 
planejados e descritos nos planos de negócio (objetivos, estratégias e metas) e de TI (definições das necessidades de TI para suporte aos itens de negócio), durante a etapa de formulação das estratégias para determinado horizonte de planejamento (Zviran, 1990; Reich e Benbasat, 1996; Chan et al., 1997).

. Elementos da Etapa de Implementação do Processo de PE: estes elementos representam a promoção do alinhamento por meio de variáveis de metodologia de implementação dos planos e dos SII, que permitam a manutenção da adequação contínua dos itens planejados na etapa anterior, garantam a integração funcional e informacional pela conformidade dos itens planejados com os processos e modelo de informações definidos nos SII, mantenham a participação, o monitoramento e comprometimento das pessoas com as metas a atingir durante todo o horizonte de planejamento (Lederer e Sethi, 1996; Gottschalck e Lederer, 1997; Segars e Grover, 1998).

\section{Metodologia de Pesquisa}

Esta pesquisa foca a TI e o alinhamento estratégico, adotando para tanto uma visão interpretativa e construtivista (Reich e Benbasat, 1996; Brodbeck, 2001). A alternativa de multimétodos foi utilizada, constituindo-se de experiências vivenciadas (Chan, 1999; Audy, 2001) e de estudos de caso (Yin, 2001), uma vez que se buscou interpretar a realidade sob diferentes ângulos, permitindo uma abordagem mais genérica de todo o contexto examinado.

O método de pesquisa denominado experiências vivenciadas foi adotado, por levar em conta os conhecimentos anteriormente adquiridos pelos pesquisadores. A abordagem de estudos de caso foi empregada devido às características fundamentais desta pesquisa: um estudo em seu ambiente natural como fonte de dados; uma descrição das situações e uma revisão, durante o estudo, da fundamentação conceitual das principais dimensões que permeiam o modelo de pesquisa.

\section{Etapas da Pesquisa}

A pesquisa foi dividida em três etapas. A primeira etapa, conceitual, serviu de suporte à concepção e ao desenvolvimento do modelo de pesquisa, partindo de modelos clássicos teóricos de alinhamento e da descrição de duas experiências vivenciadas à luz destes modelos. Como resultado obteve-se o modelo preliminar para a pesquisa, os elementos de alinhamento e as variáveis de pesquisa correspondentes, que serviram de base para a criação de um protocolo inicial para a coleta dos dados. Nesta etapa também foi realizado um pré-teste do protocolo de 
coleta de dados por meio da sua revisão por um especialista em TI, professor da área e diretor de TI de um grupo multinacional; do seu uso e da sua adequação e do modelo preliminar por meio da descrição das experiências vivenciadas; da revisão do modelo preliminar e dos seus principais elementos de alinhamento por um professor e pesquisador de uma universidade estrangeira, cujas pesquisas sobre implementabilidade de planos estratégicos foram adotadas como base para esta pesquisa.

Como resultado obteve-se quatro grupos de elementos de alinhamento, que fundamentaram o instrumento de pesquisa semi-estruturado, que serviu de roteiro para as entrevistas e para a análise de documentos. Também se estruturou um modelo de alinhamento incorporando duas etapas do processo de planejamento.

A segunda etapa serviu para a realização de três estudos de caso, nos quais foi observada a promoção do alinhamento.

A terceira etapa propiciou o desenvolvimento do modelo operacional de alinhamento estratégico, um dos objetivos desta pesquisa. Foi realizada uma complexa análise de dados para a obtenção dos elementos de alinhamento convergentes ou divergentes entre a teoria, as experiências vivenciadas e os estudos de caso, significativos para o detalhamento do modelo.

\section{Seleção das Empresas e dos Entrevistados}

A seleção das empresas participantes foi elaborada procurando-se manter as características de compatibilidade com pesquisas anteriores realizadas por Brown e Magill (1994), Reich e Benbasat (1996) e Chan (1999). Para tanto, foram considerados os seguintes fatores-chaves: porte, entre médio e grande; mais de três unidades de negócio (unidades fabris, nesta pesquisa); número de funcionários, acima de 1.000; faturamento, acima de US $\$ 100$ milhões/ano; processos de planejamento formalizados, tanto de negócio quanto de TI; maturidade no processo de planejamento estratégico (mais de 3 ciclos); área de TI estruturada; usar ou estar implementando um SII. Vale ressaltar que o ambiente de gestão destas empresas é complexo, requerendo esforço de padronização de gestão devido ao grande número de unidades e divisões.

As experiências vivenciadas foram realizadas numa organização governamental do setor financeiro (serviços) e numa empresa do setor fumageiro (industrial), de capital privado. A condução dos relatos foi feita pelos pesquisadores e por um pesquisador-avaliador. As fontes de dados de cada caso foram compostas por instrumentos de levantamentos de dados utilizados na fase de diagnóstico do processo de planejamento estratégico, por documentos resultantes da etapa de formulação 
do processo de planejamento estratégico tais como relatórios, atas de reuniões, email, pela metodologia de implementação e documentos de acompanhamento.

Foram identificadas dez empresas multinacionais para os estudos de caso. Por atenderem a todas as condições pré-determinadas, foram selecionadas três empresas da área industrial, uma indústria do setor metal mecânico, uma indústria do setor de alimentos, especificamente de sementes híbridas, e uma indústria de componentes automotivos (vide Quadro 1, em seção a seguir, para maiores detalhes). As diferenças entre os tipos de produtos e negócios destas empresas serviram para buscar um modelo operacional de alinhamento potencialmente mais abrangente.

Os entrevistados foram selecionados conforme o seu conhecimento do processo de planejamento, todos eles sendo executivos do alto escalão (presidente, diretores e seus principais assessores). Para todos os respondentes foi garantido o anonimato. Previamente, foram entregues o guia de entrevista (instrumento de pesquisa) e um resumo dos propósitos da pesquisa. Buscou-se, assim, reforçar a legitimação dos resultados do estudo. Foram realizadas três entrevistas individuais com os presidentes das empresas analisadas, com duração de duas horas cada; nove entrevistas coletivas com os diretores de negócio (CEOs) e seus assessores, com duração de até duas horas e meia por empresa; e três entrevistas coletivas com os diretores de TI (CIOs). O processo completo de coleta de dados durou cerca de três meses para cada empresa.

\section{Coleta de Dados}

Para a coleta de dados foram utilizadas duas fontes: uma fonte primária, contendo os dados resultantes das entrevistas em profundidade e fontes secundárias, compostas por documentos das empresas. Isto permitiu uma triangulação entre os dados.

As entrevistas foram gravadas com uso de dois gravadores simultaneamente, e degravadas por completo pelos pesquisadores. Durante a sua transcrição, alguns respondentes foram contatados por e-mail para confirmação de algumas informações.

Os dados secundários foram obtidos por meio da leitura e análise dos seguintes documentos: planos de negócio e de TI, relatórios de avaliação dos planos e projetos, apresentações dos planos, apresentações formais das empresas, atas de reuniões, e-mails trocados entre usuários e CIOs sobre itens dos planos, planilhas de controle das informações de gestão, relatórios gerenciais de sistemas, apresentações sobre metodologias de implementação de projetos e dos planos.

\section{Análise dos Dados}

Para a análise, os dados primários e os secundários foram transcritos para uma 
unidade comum, tendo por padrão as variáveis do instrumento de pesquisa. No que se refere aos dados primários, para cada variável pesquisada havia uma resposta dos entrevistados ou uma referência a algum documento ou relatório onde a resposta poderia ser obtida. A transcrição, a codificação e a classificação dos dados secundários foram complexas devido à variedade de fontes pesquisadas.

A análise dos dados fundamentou-se nas seguintes técnicas: (1) análise de conteúdo, para identificar a presença alta, parcial ou baixa do alinhamento em cada variável, realizada pelos pesquisadores e por um pesquisador-avaliador; (2) análise léxica, para confirmar as palavras mais citadas, que continham as idéias principais de cada questão; e (3) análise categórica, para permitir a verificação da aderência entre as respostas dos CEOs e dos CIOs para uma mesma variável. A sua aplicação manteve a seqüência acima, sendo que as análises léxica e categórica foram utilizadas para confirmar a análise de conteúdo.

Os procedimentos adotados para a análise de conteúdo tiveram como referência Reich e Benbasat (1996) e Chan (1999), de cujas obras foram extraídas as etapas principais para esta pesquisa: (1) interpretação e avaliação inicial do conjunto de dados coletados nos documentos escritos, para familiarização com os modelos de planejamento e com o jargão utilizados pelos executivos das empresas; (2) transcrição e análise das entrevistas gravadas e das anotações; (3) adequação da terminologia à teoria, classificando os dados coletados segundo as variáveis delineadas (uniformização); (4) análise interpretativa focando os resultados, se possível por mais de um avaliador (replicabilidade), em momentos diferentes (estabilidade); e (5) observação e análise crítica do conteúdo com relação aos efeitos não esperados a priori.

Durante a análise de conteúdo, palavras-chaves representativas do significado de cada variável contida no instrumento de pesquisa foram grifadas pelos pesquisadores e pelo pesquisador-avaliador, com o intuito de verificar a sua convergência com a análise léxica realizada posteriormente. Todos os cuidados acima foram tomados no sentido de trazer maior confiabilidade e validade aos resultados.

\section{O Alinhamento Observado nos Estudos de Caso}

Nesta seção discutem-se os resultados obtidos a partir dos estudos de caso. O alinhamento foi definido, anteriormente, como tendo duas dimensões no processo de planejamento: a etapa de formulação e a etapa de implementação. Para cada uma foi definido um conjunto de elementos indicativos da presença do alinhamento baseados em estudos anteriores (Zviran, 1990; Henderson e Venkatraman, 
1993; Lederer e Sethi, 1996; Chan, 1999) e, então, foi verificada a presença de variáveis de alinhamento por elemento, nos processos de planejamento ocorridos em cada uma das empresas estudadas. Além destes, foram analisadas algumas práticas de alinhamento relacionadas com os elementos de contexto organizacional e do modelo de planejamento estratégico (King, 1988; Boar, 1994), que podem implicar na promoção de alinhamento com maior intensidade.

Os elementos de promoção de alinhamento presentes no modelo operacional do alinhamento estratégico, foram verificados a partir dos resultados obtidos na observação dos três estudos de caso e, anteriormente, nas duas experiências vivenciadas. Os elementos promotores de alinhamento foram mensurados a partir da identificação de pontos fortes (ALTO) e fracos (PARCIAL e BAIXO) nas três empresas, observando a sua presença em maior ou menor intensidade, quando da aplicação do instrumento de pesquisa. Exemplificando, para a variável Reuniões de Alinhamento foi assumido um alinhamento Alto para um intervalo entre reuniões de 15 dias ou menos, com pauta detalhada por objetivo de negócio e necessidade de TI correspondente, distribuição prévia da pauta e presença de todos os participantes; alinhamento Parcial para intervalos entre 15 dias e um mês, pauta delineada em grandes tópicos, sem distribuição prévia e com presença parcial; e alinhamento Baixo o restante. Estes 15 dias serviram de ponto de corte, porque permitem o desenvolvimento e o acompanhamento, sem interrupções, de atividades correspondentes a uma estratégia.

No decorrer da pesquisa verificou-se que o alinhamento sempre ocorre, isto é, não foi encontrado alinhamento nulo. Isto deve-se ao caráter subjetivo de gestão dos CEOs e dos CIOs, muitas vezes informal e instintivo, de promover ajuste entre os negócios e a TI. Apesar de nenhuma das empresas estudadas ter promovido o alinhamento total, ou seja, apresentar alinhamento Alto em todas as variáveis pesquisadas, considerando os quatro elementos de alinhamento, os resultados evidenciaram a ocorrência de promoção do alinhamento com maior ou menor intensidade para todas as empresas, dando assim sustentação ao modelo de operacionalização do alinhamento estratégico (vide Figura 1, apresentada em seção adiante). Os resultados descritos a seguir foram obtidos a partir da verificação da intensidade de promoção de alinhamento para aquelas variáveis que tiveram a presença de intensidade Alta em pelo menos duas das empresas estudadas.

O Quadro 1 mostra um panorama do contexto organizacional e do modelo de PE para cada uma das empresas estudadas. Os resultados mais significativos encontrados para os elementos de contexto organizacional e do modelo de PE, mostraram que as três empresas estudadas têm planos estratégicos formais, instrumentos para avaliação periódica dos objetivos planejados e que o processo de PE encontrava-se subdividido em etapas claras e bem definidas. Nos três estu- 
dos de caso foram analisados processos corporativos de planejamento estratégico, subdivididos por divisões, áreas e departamentos. Além disto, duas das empresas estudadas com o maior número de variáveis com alinhamento Alto, adotaram planos de incentivos individuais e coletivos para o atingimento das metas planejadas. Estes resultados também podem ser observados para uma das empresas utilizada como experiência vivenciada.

\section{Quadro 1: Descrição do Contexto dos Três Estudos de Caso}

\begin{tabular}{|c|c|c|}
\hline Empresa & Descrição & Algumas Práticas Relacionadas com Alinhamento \\
\hline $\begin{array}{l}\text { EC1: } \\
\text { Indústria } \\
\text { Metal- } \\
\text { Mecânica, } \\
\text { Multinacional } \\
\text { de Capital } \\
\text { Brasileiro }\end{array}$ & $\begin{array}{l}\text { Estabelecida há } 72 \\
\text { anos. } \\
\text { Faturamento } 500-1 \\
\text { bilhão de dólares } \\
\text { ano. } \\
11 \text { unidades } \\
\text { industriais (1 no } \\
\text { exterior), } 6 \text { centros de } \\
\text { distribuição nacionais } \\
\text { e vários no exterior. } \\
\text { Mais de } 4.000 \\
\text { funcionários. } \\
2 \text { ClOs em nível } \\
\text { corporativo. }\end{array}$ & $\begin{array}{l}\text { Vice-Presidentes, Diretores e CIOs se reportam ao Presidente do Conselho. Todos } \\
\text { estão na empresa há mais de } 15 \text { anos. A empresa é composta por Diretorias } \\
\text { Normativas, estabelecidas na sede do grupo, e Diretorias Executivas, estabelecidas } \\
\text { em Unidades. } \\
\text {. Os CIOs (2) atendem pessoalmente as necessidades de usuários até o nível } \\
\text { gerencial. A comunicação entre eles não é muito formalizada e freqüente. } \\
\text {. Cultura familiar, resistente à mudanças. } \\
\text { - Gestão centralizada focada em RH e Produção, pratica política de incentivos por } \\
\text { meio da valorização dos funcionários, baixa rotatividade por ano (próxima de } 0 \% \text { ). } \\
\text { - Custos de operação do negócio: por volta de } 67 \% \text { / faturamento ano. } \\
\text { - Estrutura da TI: } 16 \text { funcionários, dados centralizados, informação distribuída, e-mail } \\
\text { difundido, sem Intranet, EIS não integrado ao SII, redes LAN e WAN. } \\
\text { - O sistema integrado foi desenvolvido in-house, usando a tecnologia do próprio } \\
\text { banco de dados (sem camadas), apresentando alguns problemas de fragilização na } \\
\text { integração de alguns processos. Implementação interna do SII. } \\
\text { - Investimentos em TI entre } 0,2 \text { - } 1 \% \text { faturamento ano. } \\
\text { - As estratégias básicas são de crescimento por meio de diversificação de produtos e } \\
\text { de marca. } \\
\text { Três processos de planejamento estratégico, avaliação quadrimestral. }\end{array}$ \\
\hline $\begin{array}{l}\text { EC2: Indústria } \\
\text { de Alimentos - } \\
\text { sementes } \\
\text { híbridas, } \\
\text { Multinacional } \\
\text { de Capital } \\
\text { Americano }\end{array}$ & $\begin{array}{l}\text { Estabelecida no } \\
\text { Brasil, na década de } \\
1940 . \\
\text { Faturamento de até } \\
500 \text { milhões de } \\
\text { dólares ano para as } 5 \\
\text { unidades industriais } \\
\text { instaladas no Brasil. } \\
\text { Mais de } 1.000 \\
\text { funcionários. } \\
1 \text { ClO para América } \\
\text { do Sul. }\end{array}$ & $\begin{array}{l}\text { Diretor Geral, Gerentes e ClOs se reportam ao Presidente da América do Sul. } \\
\text { Todos estão na empresa há mais de } 15 \text { anos. } \\
\text {. A CIO (1) atende pessoalmente as necessidades de usuários até o nível gerencial. } \\
\text { A comunicação entre eles não é muito formalizada, mas é freqüente. } \\
\text { - Cultura profissional orientada para resultados, não resistente à mudanças. } \\
\text { - Gestão centralizada com visão comercial e operacional, pratica política de } \\
\text { incentivos por atingimento de metas, não havendo rotatividade nos } 2 \text { últimos anos. } \\
\text {. Custos de operação do negócio: por volta de } 60 \% / \text { faturamento ano. } \\
\text { - Estrutura da TI: } 6 \text { funcionários, dados centralizados, informação distribuída, e-mail } \\
\text { difundido, Intranet em fase inicial, EIS semi integrado ao SII, redes LAN e WAN. } \\
\text { - O sistema integrado foi desenvolvido por software-house, usando tecnologia de } \\
\text { ponta de três camadas. Implementação do SIl por terceiros. } \\
\text { - Investimentos em TI entre } 1-2 \% \text { faturamento ano. } \\
\text { - As estratégias básicas são: inovação tecnológica, qualidade e desempenho, } \\
\text { eficiência e rentabilidade. } \\
\text { Cinco processos de planejamento estratégico, avaliação mensal. }\end{array}$ \\
\hline $\begin{array}{l}\text { EC3: Indústria } \\
\text { de } \\
\text { Componentes } \\
\text { Automotivos, } \\
\text { Multinacional, } \\
\text { de Capital } \\
\text { Alemão }\end{array}$ & $\begin{array}{l}\text { Estabelecida no } \\
\text { Brasil há } 81 \text { anos. } \\
\text { Faturamento entre } \\
500 \text { milhões }-1 \\
\text { bilhão de dólares } \\
\text { ano. } \\
9 \text { unidades industriais } \\
\text { no Brasil e } 1 \text { centro } \\
\text { de distribuição. } \\
\text { Mais de } 8.000 \\
\text { funcionários. } \\
2 \text { ClOs em nível } \\
\text { corporativo. }\end{array}$ & $\begin{array}{l}\text { Presidente, Vice-Presidentes, Diretores Executivos e ClOs se reportam ao } \\
\text { Presidente da América do Sul (o mesmo Presidente da companhia). Todos estão na } \\
\text { empresa há mais de } 15 \text { anos. } \\
\text {. Os CIOs (2) atendem pessoalmente as necessidades de usuários até o nível } \\
\text { gerencial. A comunicação entre eles é formalizada e freqüente. Presença de um } \\
\text { CEO envolvido nos projetos da TI. } \\
\text { - Cultura profissional orientada para resultados, não resistente à mudanças. } \\
\text { - Gestão centralizada com visão industrial e financeira, pratica política de incentivos } \\
\text { por atingimento de metas, apresentando a rotatividade abaixo da do setor. } \\
\text { - Custos de operação do negócio: por volta de } 60 \% / \text { faturamento ano. } \\
\text {. Estrutura da TI: } 800 \text { funcionários, dados centralizados, informação distribuída, e- } \\
\text { mail difundido, Intranet em uso, EIS semi integrado ao SII, redes LAN e WAN. } \\
\text { - O sistema integrado foi desenvolvido por software-house, usando tecnologia de } \\
\text { ponta de três camadas. Implementação do SII por terceiros. } \\
\text { - Investimentos em TI entre } 1 \text { - } 2 \% \text { faturamento ano. } \\
\text { - As estratégias básicas são: tecnologia de produto e processo, tecnologia de } \\
\text { informação e tecnologia de recursos humanos. } \\
\text {. Cinco processos de planejamento estratégico, avaliação quinzenal, mensal e } \\
\text { trimestral. }\end{array}$ \\
\hline
\end{tabular}


Os Quadros 2 e 3 apresentam a intensidade de promoção de alinhamento, observada em cada uma das três empresas estudadas durante as etapas de formulação e de implementação do processo de PE.

Na etapa de formulação (vide Quadro 2), o conjunto de variáveis representativo da promoção do alinhamento foi agrupado nos seguintes elementos de alinhamento: itens de elo (A), representando a adequação estratégica promovida entre os itens dos planos de negócio e de TI durante as reuniões de planejamento para definições das estratégias, objetivos, metas e demais componentes do processo de PE; consistência entre os objetivos de negócio e de TI (B), representando o conjunto informacional necessário para suporte do monitoramento do atingimento dos objetivos estratégicos e de suas metas durante a etapa de implementação do processo de PE. O terceiro elemento de promoção de alinhamento para esta etapa, chamado integração funcional e medido por meio de variáveis de integração da infra-estrutura organizacional e da infra-estrutura de TI (redes e banco de dados centrais), dos processos de negócios com a camada de regras de negócio definidas nos sistemas e pela disseminação das informações e uso feito pelos usuários, foi fixado pela existência da tecnologia de informação de sistemas de informações integrados (SII) nas empresas estudadas.

\section{Quadro 2: Alinhamento Encontrado nas Empresas Estudadas, na Etapa de Formulação}

\begin{tabular}{|c|c|c|c|c|c|c|}
\hline \multirow{2}{*}{$\begin{array}{l}\text { Variáveis Promotoras de Alinhamento para os Elementos de Alinhamento da } \\
\text { Etapa de Formulação do PE }\end{array}$} & \multicolumn{6}{|c|}{ Intensidade do Alinhamento } \\
\hline & \multicolumn{2}{|c|}{ EC1 } & \multicolumn{2}{|c|}{ EC2 } & \multicolumn{2}{|c|}{ EC3 } \\
\hline \multicolumn{7}{|l|}{ A) Itens de Elo } \\
\hline A1) Missão dos planos de negócios e de TI estão fortemente vinculadas entre si & \multicolumn{2}{|c|}{ Parcial } & \multicolumn{2}{|c|}{ Parcial } & \multicolumn{2}{|c|}{ Alto } \\
\hline A2) Estratégias e plano de TI estão bem documentados & \multicolumn{2}{|c|}{ Alto } & \multicolumn{2}{|c|}{ Alto } & \multicolumn{2}{|c|}{ Alto } \\
\hline A3) O plano de negócio situa necessidades de TI e vice-versa & \multicolumn{2}{|c|}{ Alto } & \multicolumn{2}{|c|}{ Alto } & \multicolumn{2}{|c|}{ Alto } \\
\hline A4) O plano de negócio e a T| definem priorizações de ações & \multicolumn{2}{|c|}{ Parcial } & \multicolumn{2}{|c|}{ Alto } & \multicolumn{2}{|c|}{ Alto } \\
\hline A5) Os itens do plano de TI são fechados com os itens do plano de negócios & \multicolumn{2}{|c|}{ Parcial } & \multicolumn{2}{|c|}{ Baixo } & \multicolumn{2}{|c|}{ Alto } \\
\hline A6) Os gerentes de linha e de topo participam ativamente do planejamento de $\mathrm{TI}$ & \multicolumn{2}{|c|}{ Alto } & \multicolumn{2}{|c|}{ Parcial } & \multicolumn{2}{|c|}{ Alto } \\
\hline A7) CIO participa do desenvolvimento de novos produtos & \multicolumn{2}{|c|}{ Baixo } & \multicolumn{2}{|c|}{ Alto } & \multicolumn{2}{|c|}{ Alto } \\
\hline A8) O recurso tempo dos planejamentos de negócio e de TI encontra-se sincronizado & \multicolumn{2}{|c|}{ Parcial } & \multicolumn{2}{|c|}{ Alto } & \multicolumn{2}{|c|}{ Alto } \\
\hline A9) O gerenciamento de topo é educado para a importância da TI & \multicolumn{2}{|c|}{ Alto } & & Ito & & rcial \\
\hline A10) A Tl está adaptada para mudanças estratégicas & & & & Ito & & rcial \\
\hline $\begin{array}{l}\text { A11) Compreensão dos objetivos organizacionais tanto pelo gerenciamento de topo } \\
\text { do negócio quanto pelos de } \mathrm{TI}\end{array}$ & $\mathrm{Pa}$ & cial & & Ito & & Ito \\
\hline A12) Elevada visão do relacionamento das funções de TI com a organização (SII) & & & & Ito & & Ito \\
\hline A13) Avaliação da importância estratégica de tecnologias emergentes & & ixo & $\mathrm{Pa}$ & rcial & & Ito \\
\hline B) Consistência entre os objetivos de negócios e de TI & & & & & & \\
\hline B1) Redução de Custos & & & & Ito & & to \\
\hline B2) Aumento de Faturamento & $\mathrm{Pa}$ & cial & & Ito & & Ito \\
\hline B3) Eficiência & & to & & Ito & & to \\
\hline B4) Serviços & & ixo & & ixo & & cial \\
\hline B5) Supply Chain & & to & & Ito & & cial \\
\hline B6) Vantagens Competitivas & & ixo & & ixo & & cial \\
\hline B7) Qualidade de Produto & $\mathrm{Pa}$ & cial & & Ito & & cial \\
\hline B8) Produtividade & & to & & Ito & & Ito \\
\hline Freqüências & & & & & & \\
\hline Alto & 10 & $48 \%$ & 15 & $71 \%$ & 15 & $71 \%$ \\
\hline Parcial & 7 & $33 \%$ & 3 & $15 \%$ & 6 & $29 \%$ \\
\hline Baixo & 4 & $19 \%$ & 3 & $14 \%$ & - & \\
\hline
\end{tabular}

A promoção de alinhamento Alto foi verificada para aquelas variáveis re- 
presentativas da metodologia adotada para as reuniões de planejamento (A2, A3, A4, A6), como forma de intensificar a adequação estratégica entre os itens dos planos de negócio e de TI; para a representatividade do modelo informacional utilizado no monitoramento dos itens planejados durante a sua implementação (B1, B2, B3, B5 e B8); e para a representatividade do modelo de negócio transcrito na camada das regras de negócio dos SII (A10, A11 e A12). Alguns resultados desta etapa, apresentando um alinhamento ParcialBaixo, também parecem ser significativos quando relacionados com variáveis da etapa de implementação, tais como: a revisão do fechamento dos itens dos planos de TI com os de negócio (A5) e a participação dos CIOs no desenvolvimento de novos produtos (A7) pode ser associada ao atingimento parcial das metas estabelecidas para o final do horizonte de planejamento (vide Quadro 3 - C6 e E1), devido a não sincronização eficiente dos recursos e o comprometimento parcial das pessoas envolvidas; e a consistência das informações fornecidas pelos SII relacionada a serviços (B4) e vantagens competitivas (B6) também pode comprometer o atingimento das metas estabelecidas no PE, assim como a identificação de novos projetos e oportunidades futuras (vide Quadro 3 - C3 e F2).

Analisando a freqüência de alinhamento encontrada para a etapa de formulação, constata-se que as empresas estudadas, de forma geral, apresentam maior intensidade de alinhamento Alto e Parcial. O percentual médio de alinhamento Alto encontrado é de $63 \%$ e o Parcial é de $25 \%$. Esta convergência de resultados entre as empresas mostra que o alinhamento está sendo promovido durante esta etapa e quais elementos e variáveis de alinhamento oferecem maior contribuição para o processo como um todo.

Na etapa de implementação (vide Quadro 3), o conjunto de variáveis representativo da promoção do alinhamento foi agrupado nos seguintes elementos de alinhamento: metodologia (C), representando a adequação estratégica promovida entre os itens dos planos de negócio e de TI durante as reuniões de revisão das estratégias, objetivos e avaliação do atingimento das respectivas metas ao longo do horizonte de planejamento; gerenciamento (D), representando o método de monitoramento e coordenação da execução dos projetos originados em cada objetivo estratégico; comprometimento (E), representando o nível de envolvimento dos participantes do PE em cada projeto em execução nesta etapa específica do processo; e processos (F), representando os ajustes na infra-estrutura organizacional e de TI, interna ou externa, que vão se fazendo necessários durante a execução dos projetos identificados na etapa de formulação do processo de PE. 


\section{Quadro 3: Alinhamento Encontrado nas Empresas Estudadas, na Etapa de Implementação}

\begin{tabular}{|c|c|c|c|c|c|c|}
\hline \multirow{2}{*}{$\begin{array}{l}\text { Variáveis Promotoras de Alinhamento para os Elementos de Alinhamento da } \\
\text { Etapa de Implementação do PE }\end{array}$} & \multicolumn{6}{|c|}{ Intensidade do Alinhamento } \\
\hline & \multicolumn{2}{|c|}{ EC1 } & \multicolumn{2}{|c|}{ EC2 } & \multicolumn{2}{|c|}{ EC3 } \\
\hline \multicolumn{7}{|l|}{ C) Metodologia } \\
\hline C1) Leva em conta objetivos e estratégias organizacionais & \multicolumn{2}{|c|}{ Parcial } & \multicolumn{2}{|c|}{ Alto } & \multicolumn{2}{|c|}{ Alto } \\
\hline C2) Requer envolvimento dos gerentes e usuários & \multicolumn{2}{|c|}{ Alto } & \multicolumn{2}{|c|}{ Alto } & \multicolumn{2}{|c|}{ Alto } \\
\hline C3) Identifica novos projetos & \multicolumn{2}{|c|}{ Baixo } & \multicolumn{2}{|c|}{ Alto } & \multicolumn{2}{|c|}{ Alto } \\
\hline C4) Determina base uniforme para priorização dos projetos & \multicolumn{2}{|c|}{ Alto } & \multicolumn{2}{|c|}{ Alto } & \multicolumn{2}{|c|}{ Alto } \\
\hline C5) Inclui plano global de hardware, software e comunicação para a organização & \multicolumn{2}{|c|}{ Alto } & \multicolumn{2}{|c|}{ Alto } & \multicolumn{2}{|c|}{ Alto } \\
\hline C6) Os resultados estão de acordo com as expectativas do gerenciamento de topo & \multicolumn{2}{|c|}{ Parcial } & \multicolumn{2}{|c|}{ Parcial } & \multicolumn{2}{|c|}{ Alto } \\
\hline C7) Consultores externos & \multicolumn{2}{|c|}{ Baixo } & \multicolumn{2}{|c|}{ Alto } & \multicolumn{2}{|c|}{ Alto } \\
\hline \multicolumn{7}{|l|}{ D) Gerenciamento (Monitoramento e Coordenação) } \\
\hline D1) Ferramentas de TI para execução do planejamento & \multicolumn{2}{|c|}{ Baixo } & \multicolumn{2}{|c|}{ Parcial } & \multicolumn{2}{|c|}{ Parcial } \\
\hline D2) Freqüência das revisões e ajustes & \multicolumn{2}{|c|}{ Parcial } & \multicolumn{2}{|c|}{ Parcial } & & Ito \\
\hline D3) Acompanhamento das revisões (documentação e itens atendidos) & & & & cial & & Ito \\
\hline E) Comprometimento & & & & & & \\
\hline E1) Atendimento dos objetivos & $\mathrm{Pa}$ & cial & & cial & & Ito \\
\hline E2) Motivação (incentivos) & $\mathrm{Pa}$ & cial & & to & & Ito \\
\hline $\begin{array}{l}\text { E3) Dificuldades de garantir a implementação e o comprometimento dos gerentes de } \\
\text { topo }\end{array}$ & & cial & & to & & Ito \\
\hline E4) Patrocinadores da área de negócios & & to & & to & & Ito \\
\hline F) Processos & & & & & & \\
\hline $\begin{array}{l}\text { F1) Identificação de oportunidades de melhorias nos processos do negócio por meio } \\
\text { da TI }\end{array}$ & & to & & to & & Ito \\
\hline $\begin{array}{l}\text { F2) Monitoramento das necessidades internas do negócio e das capacidades de } \mathrm{Tl} \\
\text { para atender estas necessidades }\end{array}$ & & & & cial & & Ito \\
\hline $\begin{array}{ll} & \text { Freqüências } \\
\end{array}$ & & & & & & \\
\hline Alto & 7 & $44 \%$ & 10 & $63 \%$ & 15 & $94 \%$ \\
\hline Parcial & 6 & $37 \%$ & 6 & $37 \%$ & 1 & $6 \%$ \\
\hline Baixo & 3 & $19 \%$ & - & - & - & - \\
\hline
\end{tabular}

Os resultados encontrados apontam uma promoção de alinhamento Alto para aquelas variáveis representativas da metodologia utilizada para as reuniões de revisão e avaliação das estratégias e objetivos estabelecidas na etapa anterior e conseqüentes ajustes necessários para que as metas sejam atingidas (C1, C2, C4 e C5), por meio da necessidade de documentação dos ajustes efetuados durante sua execução (D3), permitindo melhor gerenciamento e monitoramento do atingimento dos resultados; por meio de incentivos individuais (E2) e apoio total dos patrocinadores-chaves dos projetos estratégicos (E4); e por meio da identificação de novas oportunidades (F1) e de melhorias internas e externas nos processos e nos projetos já em execução (F2).

Alguns resultados desta etapa apresentando um alinhamento Parcial-Baixo, merecem ser destacados como significativos para a promoção de alinhamento em maior intensidade, principalmente quando aliados aos comentários realizados pelas três empresas estudadas sobre a deficiência das ferramentas de TI (D1) para gestão estratégica do negócio, monitoramento e controle dos itens planejados na etapa de formulação. Considerando-se que o controle e monitoramento facilita o atingimento das metas planejadas, a deficiência torna-se ainda mais evidente à luz dos resultados encontrados para as variáveis C6, D1, D2 e E1.

Analisando a freqüência de alinhamento encontrada para a etapa de 
implementação, constata-se que as empresas estudadas, de forma geral, também apresentam maior intensidade de alinhamento Alto e Parcial. O percentual médio de alinhamento Alto encontrado é de 67\% e o Parcial é de 26\%. Esta convergência de resultados também mostra que a promoção do alinhamento estratégico é significativa não somente para esta etapa, como para o processo como um todo.

A análise das informações e dos resultados apresentados nesta seção, além de mostrar elementos significativos para o alinhamento e evidenciar a intensidade de alinhamento verificado nos três casos estudados, contribuiu decisivamente para a construção do modelo operacional de alinhamento desenvolvido a seguir.

\section{Alinhamento Estratégico PEN-PEti: um Modelo Operacional PARA A IMPLEMENTAÇÃO}

Inicialmente, apresenta-se o modelo operacional de alinhamento estratégico, a interpretação de seu escopo, estrutura e forma. A seguir, são introduzidos os conceitos e significados mais representativos para os quatro elementos de alinhamento do modelo, respectivamente o contexto organizacional, o modelo de planejamento estratégico e as etapas de formulação e de implementação do processo de PE, e são detalhadas as variáveis que os compõem.

\section{Modelo Operacional do Alinhamento Estratégico}

O modelo operacional de promoção do alinhamento estratégico entre negócio e TI durante as etapas de formulação e implementação do processo de planejamento estratégico (vide Figura 1) segue a concepção básica do modelo de Henderson e Venkatraman (1993) e incorpora novos conhecimentos originados dos estudos de metodologias de implementação de planos estratégicos e dos resultados obtidos a partir das observações realizadas (Brodbeck, 2001; Brodbeck e Hoppen, 2002), em parte apresentados na seção anterior. A diferença deste modelo dos demais modelos teóricos encontra-se na reinterpretação de alguns elementos de alinhamento, no acréscimo de novos elementos essenciais para a promoção de alinhamento estratégico contínuo e dinâmico, no acréscimo do alinhamento no tempo e sua continuidade por todo o período do processo de planejamento (eixo Z), e no reconhecimento da ocorrência de alinhamento para as etapas de formulação e de implementação do processo de planejamento, não excludentes, ocorrendo seqüencialmente e continuamente. 


\section{Figura 1: Modelo Operacional do Alinhamento Estratégico}

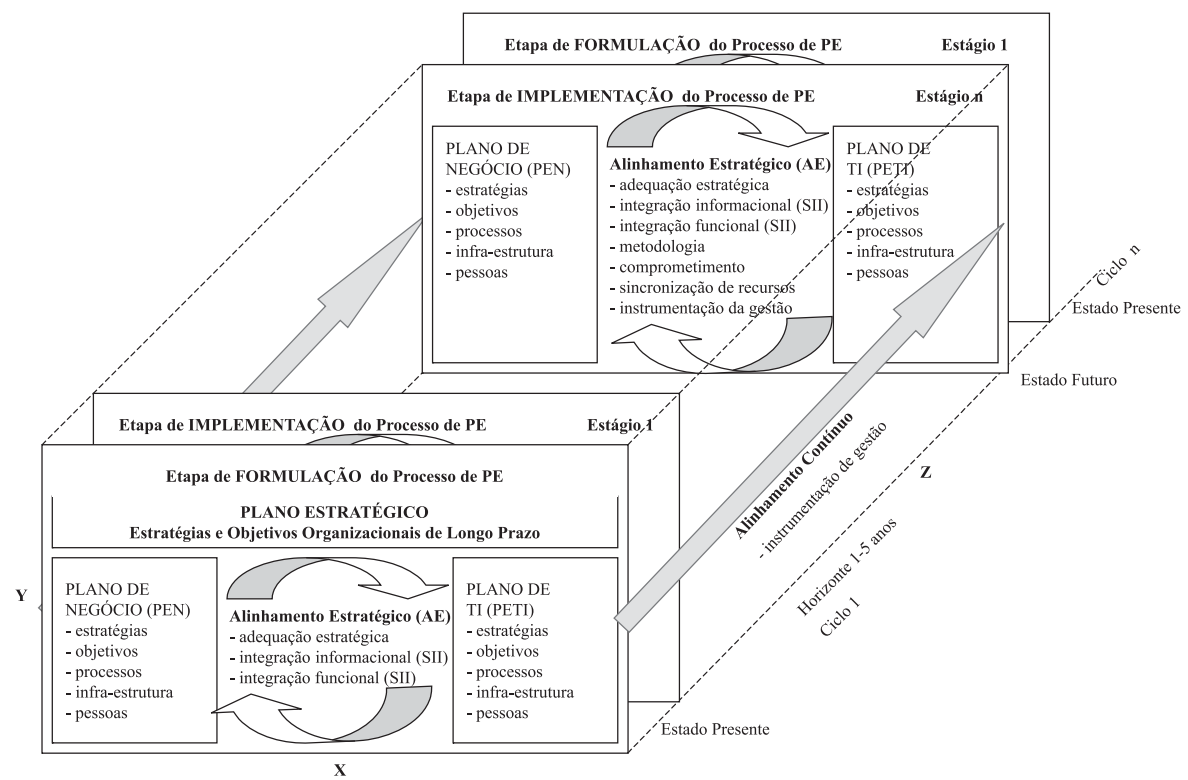

Fonte: Brodbeck (2001).

O modelo adota uma visão espacial, contendo um plano de frente representando a promoção do alinhamento entre os itens do plano de negócios e de TI durante a etapa de formulação do processo de planejamento estratégico, e vários planos de fundo representando a promoção do alinhamento contínuo durante os diferentes estágios da etapa de implementação do processo de PE. Estes estágios podem ser comparados à etapa de avaliação do modelo de planejamento estratégico de SI de King (1988) e demonstram o dinamismo do alinhamento ao longo do tempo. Desta forma, o modelo pode ser interpretado como um cubo formado pelo ciclo de cada processo de planejamento (n ciclos), representando a continuidade da promoção do alinhamento, expresso pelo:

- alinhamento circular (no plano) entre objetivos e estratégias de negócio e de TI, indicando que o redirecionamento de alinhamento pode ser feito por ambos, a qualquer instante;

- alinhamento cíclico e crescente no tempo e espaço, indicando o movimento dos itens planejados do estado presente para o estado futuro, implementando-se a visão básica de processo em movimento proposta por Boar (1994).

A promoção do alinhamento circular é representada pelo ajuste contínuo dos objetivos e recursos organizacionais com os projetos de TI, contemplando infra- 
estrutura, processos, pessoas e demais recursos necessários para o suporte do negócio. Este ajuste deve ser mantido por todo o horizonte de planejamento, independentemente da etapa do processo.

A promoção do alinhamento cíclico é representada pelo mesmo ajuste dos itens organizacionais especificados para o alinhamento circular, mas crescente no tempo. Isto significa que o alinhamento deve ser promovido durante a execução dos itens planejados, podendo requerer mudanças conforme evolui no tempo. Este alinhamento apresenta forte dependência de dois elementos: do seqüenciamento do processo de planejamento (metodologia) e da instrumentação da gestão para monitoramento da execução dos itens planejados. O sincronismo (PEN-PETI) deve ser obtido por meio de reuniões de avaliação contínuas das estratégias e dos objetivos planejados, enquanto executados, e do seu conseqüente (re)ajuste, evoluindo para os próximos estágios da etapa de implementação e assim consecutivamente.

Para processos de planejamentos com horizonte de longo prazo (3-5 anos), os objetivos estratégicos devem ser descritos por meio de projetos estratégicos, por sua vez divididos em objetivos de curto prazo (até 1 ano), possibilitando melhor controle operacional das metas estabelecidas e garantindo ajuste mais apurado entre as partes e com relação ao todo. Neste sentido, propõe-se que o planejamento de longo prazo contemple o estágio de alinhamento integral (Teo, 1994), isto é, um plano único, no qual a TI esteja incorporada como uma estratégia de base, subdividida em projetos estratégicos. Nos planos de ação anuais estes projetos passam a ter seus recursos distribuídos pelas áreas de negócio.

Com relação aos objetivos estratégicos, o modelo propõe que sejam estabelecidas metas fixas e variáveis, também subdivididas em períodos de curto prazo, para seu melhor monitoramento e ajuste ao longo do processo de planejamento. As metas fixas, consideradas estáticas, são aquelas propostas no início do período de planejamento, contendo as proposições a serem alcançadas no final do horizonte de planejamento. As metas variáveis, consideradas dinâmicas, são estas mesmas, alteradas à medida que o processo está sendo executado e que os redirecionamentos estratégicos se realizam. O alinhamento total será obtido quando as informações representativas do modelo de gestão estratégico da organização, fornecidas pelo SII e por outros sistemas estratégicos, permitirem o ajuste permanente das metas executadas com relação ao padrão estabelecido, favorecendo o seu atingimento integral.

\section{Elementos de Alinhamento Estratégico}

O modelo é formado por um conjunto de elementos promotores de alinhamento 
estratégico, descritos a seguir. Todos os elementos contém um conjunto de variáveis significativas para a promoção do alinhamento. O primeiro elemento apresenta variáveis relacionadas a um contexto organizacional mais propício para a promoção do alinhamento. O segundo elemento apresenta variáveis de especificação do modelo de planejamento estratégico mais propícias ao alinhamento estratégico. Os dois últimos elementos apresentam variáveis relacionadas às etapas de formulação e de implementação do processo de planejamento estratégico. Devido à sua complexidade, estes elementos foram consolidados em grupos específicos (vide primeira coluna dos Quadros 5 e 6).

\section{Contexto Organizacional}

Este elemento, não visível no modelo (vide Figura 1), representa o ambiente de planejamento para a promoção do alinhamento estratégico entre PEN-PETI. Foram identificadas as variáveis descritas a seguir, correspondentes ao contexto organizacional (vide Quadro 4), significativas para que haja promoção do alinhamento estratégico em maior intensidade.

\section{Quadro 4: Variáveis do Contexto Organizacional}

\begin{tabular}{|l|l|}
\hline Variável & Interpretação \\
\hline $\begin{array}{l}\text { Documentos formais de } \\
\text { planos }\end{array}$ & $\begin{array}{l}\text { Existência de formalização dos itens planejados por meio de documentos escritos } \\
\text { denominados planos de negócio e de TI, que contenham as estratégias de negócio, } \\
\text { objetivos e metas, ações, recursos e responsabilidades e uma definição clara das } \\
\text { necessidades de TI para suporte de cada um dos itens planejados. }\end{array}$ \\
\hline Cultura única de gestão & $\begin{array}{l}\text { Existência de uma cultura organizacional estabelecida, representada por um modelo } \\
\text { corporativo de gestão e de informações, que propicie aos executivos maior conhecimento e } \\
\text { monitoramento dos objetivos e metas organizacionais e individuais (área de negócio ou } \\
\text { departamento), mantendo o foco no todo. }\end{array}$ \\
\hline $\begin{array}{l}\text { Política de incentivos e de } \\
\text { cobrança de resultados }\end{array}$ & $\begin{array}{l}\text { Existência de programas de incentivos e de cobrança de resultados individuais e coletivos } \\
\text { associados às metas estabelecidas no planejamento estratégico. }\end{array}$ \\
\hline $\begin{array}{l}\text { Modelagem das regras do } \\
\text { negócio dentro do SII }\end{array}$ & $\begin{array}{l}\text { Representatividade do: (1) modelo de negócio mediante a conformidade dos processos } \\
\text { descritos no SII, das funções com a estrutura organizacional, ambas se refletindo na } \\
\text { melhoria da compreensão da operação e gerenciamento do negócio pelas pessoas; e (2) da } \\
\text { integridade e consistência do modelo informacional ao modelo de gestão e aos objetivos e } \\
\text { metas estabelecidas no planejamento estratégico. }\end{array}$ \\
\hline Postura proativa & $\begin{array}{l}\text { Proatividade frente à concorrência por meio da representação, no modelo informacional, do } \\
\text { ambiente externo e dos mercados. }\end{array}$ \\
\hline
\end{tabular}

\section{Modelo de Planejamento Estratégico}

O modelo de planejamento estratégico é formado pelos planos e processos de planejamento e, na Figura 1, encontra-se inserido nas etapas de formulação e de implementação. As variáveis correspondentes ao elemento, significativas para a promoção do alinhamento estratégico, não mudaram ao longo da pesquisa.

A estrutura dos planos contém estratégias, objetivos e metas corporativas subdivididas por estratégias, objetivos, metas e planos de ação por unidades (divisões, departamentos ou áreas). O processo de planejamento envolve pelo menos 
as seguintes etapas: diagnóstico e formulação, seguidas de implementação dos itens planejados na formulação e avaliação do seu atingimento no final do horizonte de planejamento, completando um ciclo do processo como um todo.

No entanto, algumas extensões à estrutura dos planos e ao processo de planejamento são sugeridas pelo modelo proposto, para que a promoção do alinhamento seja intensificada, conforme especificado abaixo.

- Os planos de negócio e de TI de longo prazo (5 anos ou mais) devem ser integrados, tratando a TI como uma das estratégias genéricas do negócio, visando ao nível de alinhamento total.

- A separação entre as estratégias e os objetivos de negócio e de TI deve ser feita nos projetos, desmembrando cada objetivo ou projeto estratégico em projetos ou objetivos de nível gerencial-operacional com metas de curto prazo (até 1 ano), visando a melhorar a sincronização entre eles e entre as áreas durante a sua execução.

- O monitoramento do horizonte de planejamento em blocos de tempo menores, melhorando o acompanhamento das atividades e o ajuste mais efetivo e rápido das metas executadas.

- Os planos de ação devem ser detalhados em atividades, recursos e responsabilidades, conforme as metas de curto prazo (semanais, mensais) estabelecidas por unidade, área ou departamento.

- A modelagem do conjunto informacional durante a etapa da formulação, que possibilitará a sincronização das metas de curto e de longo prazo, das metas das unidades, áreas e departamentos com as metas corporativas, permitindo o monitoramento contínuo do atingimento dos objetivos estratégicos e gerenciais planejados durante a etapa de implementação.

\section{Elementos deAlinhamento na Formulação do Processo de Planejamento Estratégico}

O elemento de alinhamento, representado no plano de frente do modelo da Figura 1, identificado como sendo a Etapa de Formulação do Processo de Planejamento Estratégico (PE), está relacionado ao método utilizado no processo de planejamento estratégico. Devido a isto, ele foi desmembrado em três grupos de elementos promotores de alinhamento, com suas respectivas variáveis (vide Quadro 5), significativos para que haja a promoção do alinhamento estratégico de maior intensidade. 


\section{Quadro 5: Elementos e Variáveis na Etapa de Formulação do Processo de PE}

\begin{tabular}{|c|c|}
\hline Elemento & Variável e sua Interpretação \\
\hline $\begin{array}{l}\text { Adequação Estratégica } \\
\text { promovida por: }\end{array}$ & $\begin{array}{l}\text { Reuniões de Alinhamento: existência de reuniões cujas pautas apresentem a lista de } \\
\text { necessidades futuras de TI de suporte às estratégias e objetivos planejados de cada } \\
\text { unidade, área, departamento ou divisão do negócio. } \\
\text { Participação: participação ativa dos CEOs nas definições das TI necessárias para suporte } \\
\text { do negócio, como também a participação ativa dos CIOs na elaboração de novos negócios, } \\
\text { visando à agregar valor ao negócio. } \\
\text { Metodologia: existência de uma metodologia adequada para a etapa que contemple pelo } \\
\text { menos } 2 \text { blocos de reuniões: de definição de estratégias e objetivos corporativos de longo } \\
\text { prazo sem separações entre as áreas, promovendo alinhamento total entre negócio e TI; e } \\
\text { de derivação dos projetos estratégicos dos objetivos estratégicos, desmembrando-os em } \\
\text { projetos por áreas de negócio, identificando os projetos permanentes de Tl e elaborando os } \\
\text { planos de ação por projeto. }\end{array}$ \\
\hline $\begin{array}{l}\text { Integração Funcional por meio } \\
\text { de: }\end{array}$ & $\begin{array}{l}\text { Sistemas de Informações Integrados: encapsulamento do modelo de negócio que } \\
\text { permita o ajuste automático da camada interna representativa da operação do negócio } \\
\text { (infra-estrutura, processos e pessoas) e a gestão alinhada dos recursos operacionais que, } \\
\text { integrados aos projetos do planejamento, permitem a gestão integrada do negócio. } \\
\text { Centralização e Compartilhamento dos Dados Corporativos: banco de dados } \\
\text { corporativos melhorando a integridade e consistência das informações geradas pelo } \\
\text { sistema, para uso na tomada de decisão. }\end{array}$ \\
\hline $\begin{array}{l}\text { Integração Informacional por } \\
\text { meio de: }\end{array}$ & $\begin{array}{l}\text { Modelagem do Conjunto de Projetos e Metas dentro de Ferramentas de TI: } \\
\text { especificação do conjunto de informações a ser fornecidas pelos sistemas para o } \\
\text { monitoramento do atingimento das metas, mantendo a consistência entre os objetivos } \\
\text { estratégicos básicos do negócio e os objetivos de TI. } \\
\text { Base Uniforme de Gestão: instrumentação da gestão permitindo uniformidade do controle } \\
\text { dos resultados durante a execução incremental dos itens planejados, mantendo a coerência } \\
\text { com a visão de negócio estabelecida para longo prazo. }\end{array}$ \\
\hline
\end{tabular}

\section{Elementos de Alinhamento na Implementação do Processo de Planejamento Estratégico}

O elemento de alinhamento, representado nos vários planos de fundo do modelo da Figura 1, identificado como sendo a Etapa de Implementação do Processo de Planejamento Estratégico (PE), também está relacionado ao método do processo de planejamento estratégico. Devido a isto, ele foi desmembrado em sete grupos de elementos promotores de alinhamento, sendo três destes grupos os mesmos do elemento de alinhamento anterior (etapa de formulação) que devem ser mantidos durante a etapa de implementação. Para os grupos restantes foram identificadas as variáveis correspondentes (vide Quadro 6), significativas para que haja a promoção do alinhamento estratégico.

Algumas considerações relativas à implementação merecem destaque: a etapa apresenta vários estágios de alinhamento correspondentes aos vários períodos, projetos e metas de curto prazo desmembrados na etapa anterior; a etapa representa o movimento contínuo para o atingimento dos objetivos de longo prazo; e a etapa representa a operacionalização do alinhamento no modelo proposto. 


\section{Quadro 6: Elementos e Variáveis na Etapa de Implementação do Processo de PE}

\begin{tabular}{|c|c|}
\hline Elemento & Variável e sua Interpretação \\
\hline Adequação Estratégica & Reuniões de Alinhamento, Participação e Metodologia. \\
\hline Integração Funcional & $\begin{array}{l}\text { Sistemas de Informações e Integrados e Centralização e Compartilhamento dos } \\
\text { Dados Corporativos. }\end{array}$ \\
\hline Integração Informacional & $\begin{array}{l}\text { Modelagem do Conjunto de Objetivos e Metas dentro de Ferramentas de TI e Base } \\
\text { Uniforme de Gestão. }\end{array}$ \\
\hline $\begin{array}{l}\text { Metodologia de } \\
\text { Implementação }\end{array}$ & $\begin{array}{l}\text { Reuniões de Avaliação: realização de reuniões freqüentes de avaliação ao longo da etapa } \\
\text { de implementação, visando ao ajuste dos objetivos e metas. } \\
\text { Comunicação: informe do desenvolvimento e ajuste das atividades ao longo de toda a } \\
\text { etapa, permitindo a manutenção do conhecimento, compreensão das mudanças e } \\
\text { manutenção no foco dos objetivos organizacionais. } \\
\text { Preparação: preparação e comunicação antecipada dos conteúdos das reuniões. }\end{array}$ \\
\hline Comprometimento & $\begin{array}{l}\text { Programas de Incentivos: realização de programas de incentivos e motivacionais para os } \\
\text { participantes do processo, relacionados com os resultados obtidos, integrados com as } \\
\text { metas estabelecidas para cada projeto do planejamento. }\end{array}$ \\
\hline Sincronização de Recursos & $\begin{array}{l}\text { Detalhamento dos Projetos de Negócio e de TI: desmembramento dos projetos em } \\
\text { atividades (processos, infra-estrutura, recursos e responsabilidades) para cada área } \\
\text { individualmente, bem como os inter-relacionamentos entre as áreas. }\end{array}$ \\
\hline Instrumentação da Gestão & $\begin{array}{l}\text { Ferramentas de TI: infra-estrutura, sistemas e software aplicativo que permitam o } \\
\text { monitoramento da execução dos itens planejados, bem como de seus ajustes, sob uma } \\
\text { base uniforme de dados. } \\
\text { Modelo Informacional: representação da estrutura dos projetos em seus diversos níveis } \\
\text { que proporcione a avaliação para o processo futuro de planejamento estratégico, } \\
\text { reforçando a idéia de continuidade e constância da promoção do alinhamento. }\end{array}$ \\
\hline
\end{tabular}

Entre os elementos acima, a instrumentação da gestão destacou-se como um elemento crítico do modelo, considerado como o centro promotor da operacionalização do alinhamento durante esta etapa. Isto nos remete aos estudos de Kaplan e Norton (1997) sobre gestão do negócio e ao uso do Painel de Controle como instrumento de planejamento e controle dos resultados. O modelo informacional representado na ferramenta de TI deve conter informações e indicadores de gestão, categorizados e quantificados por áreas ou perspectivas do negócio, permitindo medir a evolução das operações do negócio com relação às especificações do planejamento corporativo. É importante que isto ocorra em dois níveis:

. o estratégico, consolidado a partir do modelo gerencial, com indicadores comparativos e evolutivos do movimento do negócio de um estado atual para um estado futuro, contemplando as estratégias de longo prazo;

- o gerencial, consolidado a partir das informações integradas entre as base de dados e de projetos, contemplando objetivos orçamentários de curto prazo.

\section{Contribuições da Pesquisa e Conclusão}

Para concluir, nesta seção são destacadas as principais contribuições metodológicas, teóricas e práticas da pesquisa.

Como contribuição metodológica ressaltamos o enfoque holístico do projeto de 
pesquisa, adequado à condução de especificações e ao levantamento de dados de processos que requeiram mudanças. Os procedimentos adotados que merecem destaque, são os que seguem: construção de um instrumento de coleta de dados homogêneo e de qualidade (os pesquisadores disponibilizam-no, sob demanda, aos interessados); utilização de múltiplos documentos na coleta de dados; adoção de múltiplos estudos de caso; estruturação detalhada da análise de dados, evidenciando o caráter construtivista e interpretativo da pesquisa; e utilização de múltiplas técnicas e múltiplos avaliadores na releitura das avaliações. Estes procedimentos contribuem para melhorar a confiabilidade das análises e a validade dos resultados encontrados.

Esses resultados e o modelo de alinhamento proposto apresentam algumas contribuições significativas para a área de planejamento estratégico das organizações, tais como a confirmação da importância da promoção do alinhamento estratégico entre as áreas de negócio e de TI, a inclusão de variáveis de estudos realizados na área de SII e de metodologias de implementação e a incorporação das etapas do processo de planejamento estratégico como um todo. Neste sentido, uma das maiores contribuições desta pesquisa encontra-se na extensão do modelo original de Henderson e Venkatraman (1993), abrindo-o para a etapa de implementação do processo de planejamento e fornecendo elementos para a sua implementação. O foco do modelo passa a ser a promoção de alinhamento contínuo para todo o horizonte de planejamento, evidenciando a persistência do processo no ciclo de vida da organização. A dimensão alinhamento é tratada independentemente da dimensão planejamento estratégico, evidenciando a sua importância como processo único e não mais isolado para a área de negócios ou para a área de TI. A visão passa a ser de gerenciamento das estratégias do negócio, tendo a tecnologia como um recurso obrigatório para o sucesso dos negócios.

Esta pesquisa procurou desenvolver uma análise abrangente das contribuições e implicações de metodologias de implementação, tanto de planejamento estratégico como de SII, para a promoção do alinhamento. A análise dos modelos de planejamento existentes em ambas as áreas mostrou, como resultado, similaridades conceituais. Isto reforça o argumento de um processo único de planejamento. Outra contribuição teórica importante desta pesquisa diz respeito à identificação da promoção do alinhamento estratégico em nível operacional, por meio dos SII. Os resultados mostraram que, efetivamente, a promoção do alinhamento entre infra-estrutura, processos e pessoas de negócio e de TI é melhor operacionalizada por meio da manutenção de bases centralizadas de dados e de tecnologia de processos integrada ponta-a-ponta (SII), que eliminem o retrabalho e a perda de informações.

E, por fim, este estudo provê conhecimento para os gerentes e profissionais da 
área de planejamento estratégico, sejam eles da área de negócio ou de TI, mediante a identificação dos pontos fortes e fracos de promoção do alinhamento estratégico nas duas etapas do processo de planejamento (formulação e implementação) e, principalmente, por meio da indicação e estruturação da necessidade de instrumentação da gestão da execução do planejamento estratégico.

Acredita-se que o grande desafio enfrentado por pesquisadores e administradores da área, refere-se à operacionalização do alinhamento. No decorrer deste estudo os pesquisadores foram questionados sobre "qual a melhor forma de promover o alinhamento” ou se “a TI está adequada ao nosso negócio”. Os resultados obtidos permitem crer que a operacionalização do alinhamento deve se efetivar por meio da modelagem de um conjunto informacional, contendo os controles operacionais e gerenciais do negócio consolidados em indicadores, que reflitam os objetivos e as estratégias organizacionais e suas metas. Esta instrumentação da gestão, aliada a uma política de incentivos para os recursos humanos e de cobrança de resultados, deve favorecer a promoção do alinhamento em maior intensidade. "Facilitar e instrumentalizar a gestão da informação” é um dos resultados apontados por Audy (2001), em sua pesquisa sobre a implementação de uma visão de planejamento estratégico como um processo de aprendizagem interativo, visando ao desenvolvimento e à redefinição de processo de negócios. A instrumentação de gestão serve, ao mesmo tempo, de ferramenta de avaliação e de estímulo ao processo de aprendizagem, melhorando continuamente o alinhamento estratégico entre plano de negócios e de TI.

\section{ReferÊnCIAS Biblográficas}

AUDY, J.

Modelo de planejamento estratégico de sistemas de informação: contribuições da aprendizagem organizacional e do processo decisório. Porto Alegre, 2001. Tese (Doutorado em Administração) Programa de Pós-Graduação em Administração, Universidade Federal do Rio Grande do Sul.

BOAR, B. H.
Aligning technology

strategies. New York: John Wiley and Sons, 1994.

BRODBECK, A. F.

Alinhamento estratégico entre os planos de negócio e de tecnologia de informação: um modelo operacional para a implementação. Porto Alegre, 2001. Tese (Doutorado em Administração) - Programa de PósGraduação em Administração, Universidade Federal do Rio Grande do Sul. 
BRODBECK, A. F.;

HOPPEN, N.

Operacionalização de um modelo para o alinhamento estratégico entre os planos de negócio e de tecnologia de informação. In: ASSEMBLÉIA DO CONSELHO LATINO-AMERICANO DE ESCOLAS DE ADMINISTRAÇÃO, 37., 2002, Porto Alegre. Anais... Porto Alegre: CLADEA, 2002. 1 CD-ROM.

BROWN, C.V.;

MAGILL, S. L.

Alignment of the IS functions with the enterprise: toward a model of antecedents. MIS Quarterly, v. 18, n. 4, p. 371-402, Dec.1994.

CHAN, Y. E.

IS strategic and structural alignment: eight case studies. In: AMERICAS CONFERENCE ON INFORMATION SYSTEMS, 5., 1999, Wisconsin. Proceedings... Wisconsin: Association for Information Systems, 1999. 1 CD-ROM.

CHAN, Y. E. et al.

Business strategic orientation, information system strategic orientation, and strategic alignment. Information Systems Research, v. 8, n. 2, p. 125-150, June 1997.

\section{GARTNER GROUP.}

Pages: 52 strategy, trends \& tactics. Keep your balance: the 2002 CIO agenda. Disponível em: <http://www.gartnergroup.com> Acesso em: 15 fev. 2002.

GOTTSCHALCK, P.;

LEDERER, A. L.

A review of literature on the implementation of strategic information system plans. In: I N T E R N A T I O N A L CONFERENCE ON INFORMATION SYSTEMS, 3., 1997, Atlanta. Proceedings... Atlanta: Association for Information Systems, 1997. 1 CDROM.

HENDERSON, J. C.; VENKATRAMAN, $\mathrm{N}$.

Strategic alignment: leveraging information technology for transforming organizations. IBM System Journal, v. 32, n. 1, p. 416, 1993.

KAPLAN, R. S.;

NORTON, D. P.

A estratégia em ação: balanced scorecard. São Paulo: Campus, 1997.

KING, W. R.

How effective is your IS planning?

Long Range Planning, v. 21, n. 5, p. 103-112, Oct. 1988.

LEDERER, A. L.;

SETHI, V.

Key prescriptions for strategic IS planning. Journal of Management Information Systems, v. 13, n. 1, p. 35-62, Summer 1996. 
MCFARLAN, F. W. Information technology changes the way you compete. Harvard Business Review, v. 62, n. 3, p. 98-103, May/June 1984.

NIEDERMAN, F.;

BRANCHEAU, J. C.;

WETHERBE, J. C.

Information systems management issues for the 1990s. MIS Quarterly, v.15, n. 4, p. 475-500, Dec. 1991.

PORTER, M. E.

Strategy in the Internet. Harvard Business Review, p. 62-78, Mar. 2001.

REICH, B. H.;

BENBASAT, I.

Measuring the linkage between business and information technology objectives. MIS Quarterly, v. 20, n. 1, p. 55-81, Mar. 1996.

SABHERWAL, R.;

CHAN, Y. E.

Alignment between business and IS strategies: a study of prospectors, analyzers and defenders. Information Systems Research, v. 12, n. 1, p. 1-33, Mar. 2001.
SEGARS, A.;

GROVER, V.

Strategic information systems planning success: an investigation of the construct and its measurement. MIS Quarterly, v. 22, n. 2, p. 139-163, June 1998.

TEO, T. S. H.

Integration between business planning and information systems planning: an evolutionary-contingency perspective. Pittsburgh, 1994. Ph.D. (Thesis) - University of Pittsburgh.

WARD, A.; GRIFFITHS, J.

Strategic planning for information system. New York: John Wiley and Sons, 1996.

YIN, R. K.

Estudo de caso: planejamento e métodos. 2. ed. Porto Alegre: Bookman, 2001.

ZVIRAN, M.

Relationships between organizational and information systems objectives: some empirical evidence. Journal of Management Information Systems, v. 7, n. 1, p. 66-84, Summer 1990. 